of the expansion contains a function of the heat sources, and for the other terms it contains the second derivative along the vertical coordinate from the previous expansion term.

Thus advection makes the main contribution to the heat transfer, and temperature in a glacier is distributed along the particle paths, changing simultaneously under the influence of heat generation. A relatively thin conducting boundary layer adjoins the upper and lower surfaces of a glacier, playing the role of a temperature damper in the ablation area. The equation of heat conduction (at the free surface) or of heat conduction and heat transfer (at the bottom) with the boundary conditions, and with the condition of the connection with the solution of the problem for the internal temperature distribution, is being solved for the boundary layer because of its small thickness. Beyond the limits of the boundary layer, heat conduction makes a small change in the temperature distribution, which can be calculated with any degree of accuracy.

\title{
TEMPERATURE DISTRIBUTION IN A SUB-ISOTHERMAL GLACIER
}

\author{
By M. S. Krass
}

(Institut Mekhaniki, Moskovskiy Gosudarstvennyy Universitet im. M. V. Lomonosova, Michurinskiy prospekt I, Moscow I I 7234 , U.S.S.R.)

Aвstract. In sub-isothermal glaciers heat conduction plays the main role in the formation of the temperature field, and the contribution of advection is relatively small. The dependence of the strain-rate on the temperature is simplified by a linear approximation. If the whole range of the temperature change in a glacier does not exceed $\approx 3 \mathrm{deg}$, with the power rheological law the quasi-steady temperature distribution is described by a simple analytical dependence. In the upper part of the ice, the temperature varies with depth almost linearly; the deflection from the linear distribution is essentially in the lower part.

\section{THERMAL CONSEQUENCES OF THE PRESSURE FLUCTUATIONS IN INTRA- AND SUBGLACIAL WATER DRAINAGE GHANNELS}

\author{
By H. RöTHLISBERGER \\ (Versuchsanstalt für Wasserbau, Hydrologie und Glaziologie an der Eidgenössischen \\ Technische Hochschule, Zürich, Switzerland)
}

Abstract. Recent measurements of the water level (pressure head) in drill holes and natural moulins on two glacier tongues in Switzerland (Oberaletschgletscher and Gornergletscher) have confirmed that in those holes which link up to a well developed subglacial drainage system the daily piezometric fluctuations are in the order of $100 \mathrm{~m}$ ( 10 bar) and more. From the fact that it is relatively easy to establish such links (in our experiments at ice depths between 150 and $300 \mathrm{~m}$ ), it is implied that an extended network of subglacial channels and cavities will be subjected to equally large pressure fluctuations with a mean water pressure considerably below the mean ice pressure at the bed. The scope of the present paper is to discuss some of the thermal effects of the low water pressure and its fluctuations. 
The effect in the ice-assuming temperate ice with a certain water content - is a positive temperature anomaly around the channel, in accordance with the stress field. The radial temperature profile in the ice around a conduit with a circular cross-section follows directly from the solution for the stress field, and the heat flux can be deduced, allowing for the ice flow towards the conduit. Pressure changes in the conduit cause a rapid change of temperature (with an associated change in water content) and a related change in heat and ice flow. In the case of a channel or cavity at the glacier bed, the temperature fluctuation produced in the channel and the surrounding ice propagates into the substratum. With rising water pressure, i.e. falling temperature, the substratum becomes a heat source and some melting will occur at the ice/rock interface in a fringe zone around channels and cavities. It is this process which may help to explain the increased sliding component of glacier motion at the time of high melt-water run-off.

Another intriguing question is what happens in a highly permeable substratum (shattered rock, moraine) at some distance away from a channel. The temperature profile is determined by the pressure melting point within the glacier down to the bed, and the positive geothermal gradient with increasing depth in the substratum below. The water pressure in the substratum is approximately equal to that in the channel, that is to say well below the mean pressure at the glacier bed. There is therefore an uppermost layer of the substratum at a temperature below the freezing temperature of the interstitial water, implying that the water must be frozen in this layer. This is one way to look at the problem. Starting out from the impermeable frozen layer it may be argued that the water film at the glacier bed is at a high pressure and the interstitial ice should melt until the water breaks through at the lower freezing boundary. This could only happen where and as long as there is no appreciable drainage of the water film and interstitial water. As soon as the water breaks through, the pressure will drop and presumably just enough leakage will be sustained to lead to a pressure drop across the frozen layer in accordance with the temperature profile. A generally impermeable glacier bed results as a most likely model, with permeable bands along subglacial drainage channels and eventual leakage holes in between. Taking the pressure fluctuations into account, one finds that temperature fluctuations have to be expected originating at the lower boundary of the frozen substratum, involving frost cycles. The erosive effectiveness of these will however be limited to the equivalent of the pressure cycles. (A double pressure amplitude of $\mathrm{I} 30 \mathrm{~m}$ of water head corresponds roughly to a double temperature amplitude of o. I deg.)

\section{RELAXATION SELF-OSGILLATIONS AND PROGESSES AT THE BOTTOM OF GLACIERS}

\section{By P. A. Shumskiy}

(Institut Mekhaniki, Moskovskiy Gosudarstvennyy Universitet im. M. V. Lomonosova, Michurinskiy prospekt I, Moscow I I 7234, U.S.S.R.)

Abstract. In terms of the theory of oscillations, rapid glacier advances (glacier surges) are relaxation self-oscillation, and large glacier advances of the same character dependent on climate are the result of interaction between forced and self-exciting oscillations.

The relation is found between average shear stress and sliding velocity of pure and of moraine-containing ice along the bottom, taking into account the real thermal and kinematic boundary conditions, the different dependence of the ice melting point on hydrostatic pressure 